\title{
Optimization of Dry Sliding Wear Performance of Ceramic Whisker Filled Epoxy Composites Using Taguchi Approach
}

\author{
M. Sudheer, Ravikantha Prabhu, K. Raju, and Thirumaleshwara Bhat \\ Department of Mechanical Engineering, St. Joseph Engineering College, Mangalore 575 028, Karnataka, India \\ Correspondence should be addressed to M. Sudheer, msudheerm2002@yahoo.co.in
}

Received 28 May 2012; Revised 5 August 2012; Accepted 9 August 2012

Academic Editor: Huseyin Çimenoğlu

Copyright () 2012 M. Sudheer et al. This is an open access article distributed under the Creative Commons Attribution License, which permits unrestricted use, distribution, and reproduction in any medium, provided the original work is properly cited.

This study evaluates the influence of independent parameters such as sliding velocity $(A)$, normal load $(B)$, filler content $(C)$, and sliding distance $(D)$ on wear performance of potassium-titanate-whiskers (PTW) reinforced epoxy composites using a statistical approach. The PTW were reinforced in epoxy resin to prepare whisker reinforced composites of different compositions using vacuum-assisted casting technique. Dry sliding wear tests were conducted using a standard pin on disc test setup following a well planned experimental schedule based on Taguchi's orthogonal arrays. With the signal-to-noise $(S / N)$ ratio and analysis of variance (ANOVA) optimal combination of parameters to minimize the wear rate was determined. It was found that inclusion of PTW has greatly improved the wear resistance property of the composites. Normal load was found to be the most significant factor affecting the wear rate followed by $(C),(D)$, and $(A)$. Interaction effects of various control parameters were less significant on wear rate of composites.

\section{Introduction}

Polymer matrix composites are an important class of composite that are finding increased use in aerospace, automotive, marine, and civil infrastructure applications. In recent years, polymer composites are extensively utilized in tribological components such as cams, brakes, bearings, and gears because of their self-lubrication properties, lower friction, and better wear resistance. More and more polymer composites are now being used as sliding components, which were formerly composed of only metallic materials $[1,2]$. Still, developments are underway to explore other fields of application for these materials and to tailor their properties for extreme load-bearing and environmental temperature conditions. Currently, usage of ceramic whisker-reinforced polymer composites is rapidly increasing.

Whiskers are short fiber-shaped single crystals with high perfection and very large length-to-diameter ratios. Generally whiskers possess high strength and stiffness due to their nearly perfect crystal structure [3]. Therefore whiskers are reckoned as more effective reinforcements than traditional fibers such as carbon fiber and glass fiber. Recently various inorganic whiskers such as Calcium Carbonate $\left(\mathrm{CaCO}_{3}\right)$,
Alumina $\left(\mathrm{Al}_{2} \mathrm{O}_{3}\right)$, Silicon Carbide ( $\mathrm{SiC}$ ), Potassium Titanate (PTW, $\left.\mathrm{K}_{2} \mathrm{Ti}_{6} \mathrm{O}_{13}\right)$, Barium Titanate $\left(\mathrm{BaTiO}_{3}\right)$, and so forth were prepared and employed in the manufacturing of composites with different polymer matrices.

Several researchers have observed the significant changes in the mechanical and tribological properties of polymers reinforced with different kinds of whiskers. Feng et al. [4] noticed that wear rate of PTW/PTFE composite decreased dramatically when PTW content increased from $1 \%$ to $20 \%$. Lin et al. [5] reported that optimal content of $\mathrm{CaCO}_{3}$ whisker in PEEK composites is $15 \%$ to $20 \%$ combining both mechanical and tribological properties. Zhang et al. [6] investigated the mechanical and wear properties of silicon carbide and alumina whisker-reinforced epoxy composites and observed that both whiskers significantly improved the flexural modulus and wear resistance of epoxy. However, Avella and coworkers [7] mentioned that addition of untreated SiC whisker into polypropylene lead to an enhancement of the modulus, but a decrease in the tensile strength. Wang et al. [8] revealed that $\mathrm{ZnO}$ whiskers have better reinforcing effect with the nylon than the $\mathrm{ZnO}$ particles. Jang et al. [9] proposed modifications with ceramic whiskers as an alternative to rubber toughening for improving the impact 
TABle 1: Properties of PTW.

\begin{tabular}{lccccc}
\hline Diameter $(\mu \mathrm{m})$ & Length $(\mu \mathrm{m})$ & Density $(\mathrm{g} / \mathrm{cc})$ & Tensile strength $(\mathrm{GPa})$ & Tensile modulus $(\mathrm{GPa})$ & Hardness $(\mathrm{Mohs})$ \\
\hline $0.5-2.5$ & $10-100$ & 3.185 & 7 & 280 & 4 \\
\hline
\end{tabular}

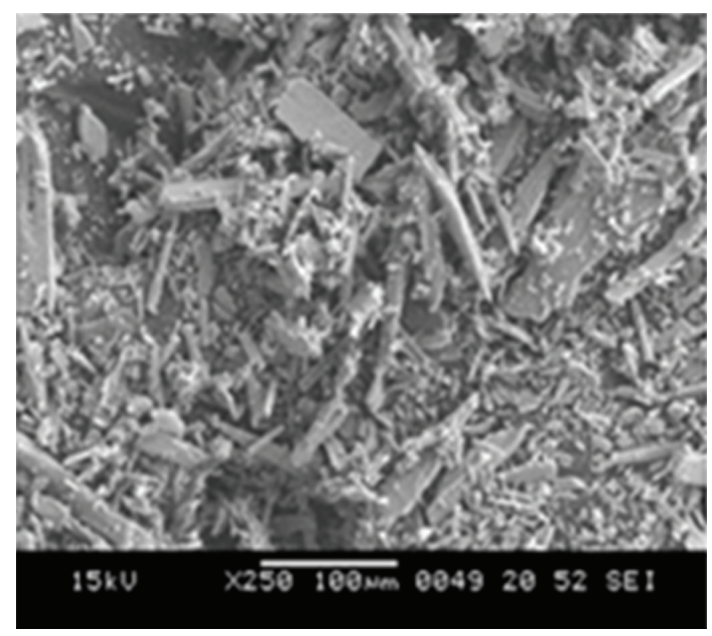

(a)

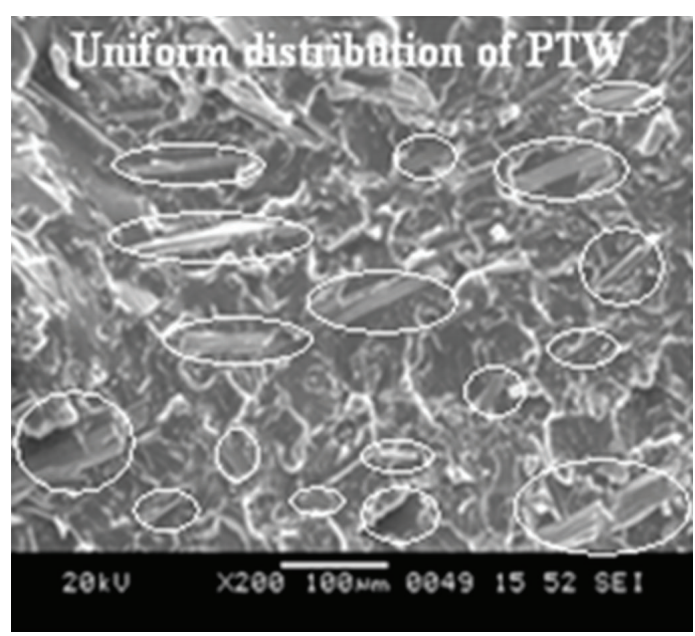

(b)

FIGURE 1: SEM picture of (a) PTW whiskers and (b) 15\% PTW filled epoxy.

resistance of epoxy resins. Among the numerous inorganic fillers, potassium titanate whisker $\left(\mathrm{PTW}, \mathrm{K}_{2} \mathrm{O} \cdot 6 \mathrm{TiO}_{2}\right)$ has been found to be a promising reinforcer for the wear resistant composites due to its unique properties, such as outstanding mechanical performance, low hardness (Mohs hardness 4), and excellent chemical stability. PTW is a kind of very fine microreinforcing material and it is suitable to reinforce the very narrow space in composites that conventional fillers are unable to do. In practice, it is an excellent fit for making products that have a complex shape, great precision, and high polished surface. The price of the PTW ranges from onetenth to one-twentieth of the cost of SiC whiskers [10]. In this regard, PTW have been used to reinforce most of the polymers [11-18].

Design of experiment is a technique to obtain the maximum amount of conclusive information from the minimum amount of work, time, energy, money, or other limited resources. The information generally comprises the relationship between product and process parameters and the desired performance characteristic [19]. Taguchi's techniques are one of the powerful tools used in the design of experiments. Taguchi's parameter design can optimize the performance characteristics through the setting of design parameters and reduce the sensitivity of system performance to the sources of variation $[20,21]$. Taguchi's experimental procedure has been successfully applied for parametric appraisal in dry sliding wear study of polymer composites [22-25]. Among the published literatures, few papers focused on tribological behavior of thermoset composites modified by ceramic whiskers. This paper discusses dry sliding wear characteristic of PTW-reinforced epoxy composites on the basis of Taguchi approach.

\section{Materials and Methods}

2.1. Materials. Room temperature curing epoxy resin system (LY556+HY951) supplied by Huntsman Advanced Materials India Pvt. Ltd., Bengaluru was used as the matrix system. PTW is a ceramic microfiller used as reinforcement was supplied by Hangzhou Dayangchem Co. Ltd., Hong Kong. These ceramic whiskers are of splinter shape (Figure 1(a)) and with high length/diameter ratio $20-40$, and properties are listed in Table 1.

2.2. Fabrication of Composites. An open mold with cavity dimensions $225 \times 225 \times 6 \mathrm{~mm}$ was fabricated to cast polymer composites. The fillers were preheated to $80^{\circ} \mathrm{C}$ for 2 hours to remove any moisture present and cooled to ambient temperature. The required quantities of filler were stirred gently into liquid epoxy resin, taking care to avoid the introduction of air bubbles. Resin filler mixture was then placed under the vacuum $(760 \mathrm{Hg} \mathrm{mm})$ for about 2 hours to remove any entrapped air. Hardener was then added to the resin in the ratio of $1: 10$ and then stirred to ensure complete mixing. The mixture was then poured into an open metallic mold coated with release agent and the mold was placed in a toughened glass chamber maintaining a low-vacuum level $400-450 \mathrm{Hg} \mathrm{mm}$ for about 1 hour. Specimens were allowed to cure under room temperature and released from mold after 24 hours. Cast composites plates obtained were of dimension $225 \times 225 \times 3 \mathrm{~mm}$. The plates were then postcured at $50^{\circ} \mathrm{C}$ for 2 hours in a hot air oven.

Composition of the test specimens was varied up to $15 \%$ of filler loading at intervals of $5 \%$. Extreme care has been taken to avoid any undesirable filler settling effect by 


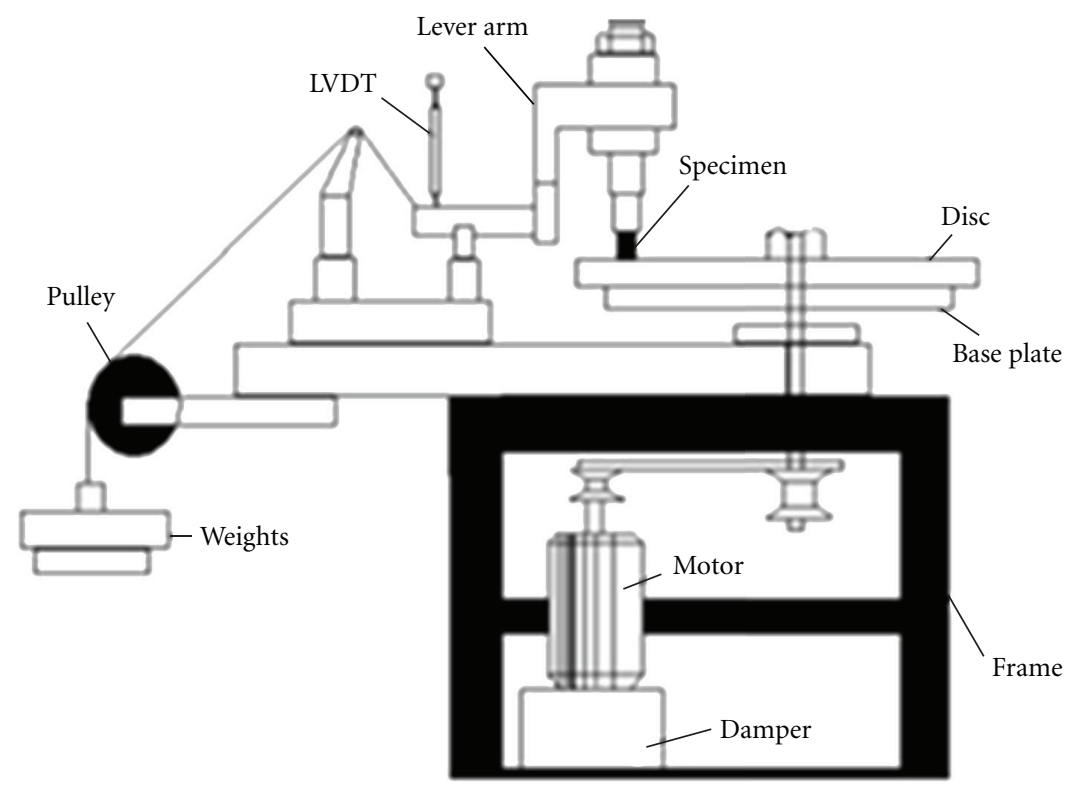

Figure 2: Pin on disc test setup.

casting the slurry just prior to its gelling stage, all time keeping it in a stirred condition. This was done to ensure the uniform composition of cast specimens across its volume. Higher PTW content means higher viscosity. Due to the processing difficulty, the composites with more than $15 \mathrm{wt} \%$ PTW were not fabricated. Wear test samples of size $10 \times$ $10 \times 3 \mathrm{~mm}$ were prepared from the cast composites using the diamond-tipped cutter. Figure 1(b) displays the SEM picture of $15 \%$ PTW-filled epoxy. It can be seen that the filler is uniformly distributed and has good compatibility with the epoxy matrix.

2.3. Wear Testing. The dry sliding wear tests were performed on pin on disc test setup (Ducom TR201C, Bangalore) as per ASTM G99-05 (reapproved 2010) standard [26]. This test setup is illustrated in Figure 2. Wear test samples of size $10 \times 10 \times 3 \mathrm{~mm}$ are glued to steel pins of $10 \mathrm{~mm}$ square cross section and $30 \mathrm{~mm}$ length and come in contact with (EN31 grade, $62 \mathrm{HRC}, 1.6 \mu \mathrm{Ra}$ ) carbon steel disc. Prior to testing, the samples were polished against fine grade sand paper (1200 grit SiC) to ensure proper contact with counterface. Test parameters are normal load: $10 \mathrm{~N}, 20 \mathrm{~N}, 30 \mathrm{~N}$; sliding velocity: $0.5 \mathrm{~m} / \mathrm{s}, 0.75 \mathrm{~m} / \mathrm{s}, 1 \mathrm{~m} / \mathrm{s}$; and sliding distance: $500 \mathrm{~m}$, $1000 \mathrm{~m}, 1500 \mathrm{~m}$. The pin along with the specimen was then weighed in an electronic balance (Shimadzu Japan, AY220, $0.1 \mathrm{mg}$ Accuracy). Before and after wear testing, samples were cleaned with acetone to remove wear debris. Weight loss of the test samples gives the measure of sliding wear loss. Volume loss was calculated from measured weight loss using density data of the test specimen. The specific wear rate $\left(W_{s}\right)$ was calculated as per

$$
W_{s}=\frac{V}{L \times d},
$$

where $V$ is the volume loss in $\mathrm{mm}^{3}, L$ is the load in Newton, and $d$ is the sliding distance in $\mathrm{m}$.
2.4. Experimental Design. Design of experiment is the powerful analysis tool for modeling and analyzing the influence of the control factors on the performance output. The most important stage in the design of experiment lies in the selection of the control factors [19]. Four parameters, namely, sliding velocity $(A)$, normal load $(B)$, filler content $(C)$, and sliding distance $(D)$ each at three levels, are considered in this study in accordance with $\mathrm{L}_{27}\left(3^{13}\right)$ orthogonal array design. Control parameters and their levels are indicated in Table 2. Four parameters each at three levels would require $3^{4}=81$ runs in a full-factorial experiment, whereas Taguchi's factorial experiment approach reduces it to only 27 runs offering a great advantage. The plan of the experiment [23, $25]$ is as follows: the first column of the Taguchi orthogonal array is assigned to the sliding velocity $(A)$, the second column to the normal load $(B)$, the fifth column to the fiber content $(C)$, the ninth column to sliding distance $(D)$ and remaining columns are assigned to their interactions and experimental errors.

The experimental observations are transformed into signal-to-noise $(S / N)$ ratio. There are several $S / N$ ratios available depending on the type of characteristic, which can be calculated as logarithmic transformation of the loss function. For lower is the better performance characteristic $S / N$ ratio is calculated as per

$$
\frac{S}{N}=-10 \log \frac{1}{n}\left(\sum y^{2}\right),
$$

where " $n$ " is the number of observations and " $y$ " is the observed data. "Lower is the better" (LB) characteristic, with the above $S / N$ ratio transformation, is suitable for minimization of wear rate. A statistical analysis of variance (ANOVA) is performed to identify the control parameters that are statistically significant. With the $S / N$ ratio and ANOVA analyses, the optimal combination of wear parameters is predicted to acceptable level of accuracy. Finally 
TABLE 2: Control factors and levels used in the experiment.

\begin{tabular}{|c|c|c|c|c|}
\hline \multirow{2}{*}{ Control factor } & \multicolumn{4}{|c|}{ Level } \\
\hline & I & II & III & Units \\
\hline$A$ : Sliding velocity & 0.50 & 0.75 & 1.00 & $\mathrm{~m} / \mathrm{s}$ \\
\hline$B$ : Normal load & 10 & 20 & 30 & $\mathrm{~N}$ \\
\hline$C$ : Filler content & 5 & 10 & 15 & $\%$ \\
\hline$D$ : Sliding distance & 500 & 1000 & 1500 & $\mathrm{~m}$ \\
\hline
\end{tabular}

TABLE 3: Test conditions with output results using $L_{27}$ orthogonal array.

\begin{tabular}{|c|c|c|c|c|c|c|}
\hline SI. no & $\begin{array}{c}\text { Sliding velocity } \\
A(\mathrm{~m} / \mathrm{s})\end{array}$ & $\begin{array}{c}\text { Normal load } \\
B(\mathrm{~N})\end{array}$ & $\begin{array}{c}\text { Filler content } \\
C(\%)\end{array}$ & $\begin{array}{c}\text { Sliding distance } \\
D(\mathrm{~m})\end{array}$ & $\begin{array}{l}\text { Specific wear rate } \\
W_{\mathrm{s}}\left(\mathrm{mm}^{3} / \mathrm{N}-\mathrm{km}\right)\end{array}$ & $\begin{array}{c}S / N \text { ratio } \\
(\mathrm{db})\end{array}$ \\
\hline 1 & 0.50 & 10 & 5 & 500 & 0.132890 & 17.5301 \\
\hline 2 & 0.50 & 10 & 10 & 1000 & 0.113821 & 18.8755 \\
\hline 3 & 0.50 & 10 & 15 & 1500 & 0.074015 & 22.6136 \\
\hline 4 & 0.50 & 20 & 5 & 1000 & 0.161960 & 15.8118 \\
\hline 5 & 0.50 & 20 & 10 & 1500 & 0.132791 & 17.5366 \\
\hline 6 & 0.50 & 20 & 15 & 500 & 0.150674 & 16.4392 \\
\hline 7 & 0.50 & 30 & 5 & 1500 & 0.118125 & 18.5532 \\
\hline 8 & 0.50 & 30 & 10 & 500 & 0.130081 & 17.7157 \\
\hline 9 & 0.50 & 30 & 15 & 1000 & 0.100449 & 19.9611 \\
\hline 10 & 0.75 & 10 & 5 & 1000 & 0.132890 & 17.5301 \\
\hline 11 & 0.75 & 10 & 10 & 1500 & 0.113821 & 18.8755 \\
\hline 12 & 0.75 & 10 & 15 & 500 & 0.095163 & 20.4307 \\
\hline 13 & 0.75 & 20 & 5 & 1500 & 0.157807 & 16.0375 \\
\hline 14 & 0.75 & 20 & 10 & 500 & 0.170732 & 15.3537 \\
\hline 15 & 0.75 & 20 & 15 & 1000 & 0.138779 & 17.1535 \\
\hline 16 & 0.75 & 30 & 5 & 500 & 0.149502 & 16.5071 \\
\hline 17 & 0.75 & 30 & 10 & 1000 & 0.121951 & 18.2763 \\
\hline 18 & 0.75 & 30 & 15 & 1500 & 0.102212 & 19.8100 \\
\hline 19 & 1.00 & 10 & 5 & 1500 & 0.132890 & 17.5301 \\
\hline 20 & 1.00 & 10 & 10 & 500 & 0.130081 & 17.7157 \\
\hline 21 & 1.00 & 10 & 15 & 1000 & 0.111023 & 19.0917 \\
\hline 22 & 1.00 & 20 & 5 & 500 & 0.224252 & 12.9853 \\
\hline 23 & 1.00 & 20 & 10 & 1000 & 0.150407 & 16.4547 \\
\hline 24 & 1.00 & 20 & 15 & 1500 & 0.132170 & 17.5773 \\
\hline 25 & 1.00 & 30 & 5 & 1000 & 0.171650 & 15.3071 \\
\hline 26 & 1.00 & 30 & 10 & 1500 & 0.130081 & 17.7157 \\
\hline 27 & 1.00 & 30 & 15 & 500 & 0.126883 & 17.9319 \\
\hline
\end{tabular}

a confirmation experiment is conducted to verify the optimal process parameters obtained from the parameter design [21].

\section{Results and Discussion}

3.1. Statistical Analysis of Wear Rate. The analysis was made using the software MINITAB 14 [27] specifically used for the design of experiment applications. Test conditions with output results using $L_{27}$ orthogonal array are presented in Table 3. From Table 3, the overall mean for the $S / N$ ratio of the wear rate was found to be $17.68 \mathrm{~dB}$. Figures 3(a) and 3 (b) show graphically the effect of the control factors on specific wear rate. Process parameter settings with the highest $S / N$ ratio always give in the optimum quality with minimum variance. The graphs show the change of the $S / N$ ratio when the setting of the control factor was changed from one level to the other. The best wear rate was at the higher $S / N$ values in the response graphs. From the plots it is clear that factor combination of $A_{1}, B_{1}, C_{3}$, and $D_{3}$ gives minimum specific wear rate. Thus minimum specific wear rate for the developed composites is obtained when the sliding velocity $(A)$ and normal load $(B)$ are at the lowest level, and filler content $(C)$ and sliding distance $(D)$ are at the highest level.

The effect of increasing the control variables on the specific wear rate can be observed from Figure 3(b). It is 

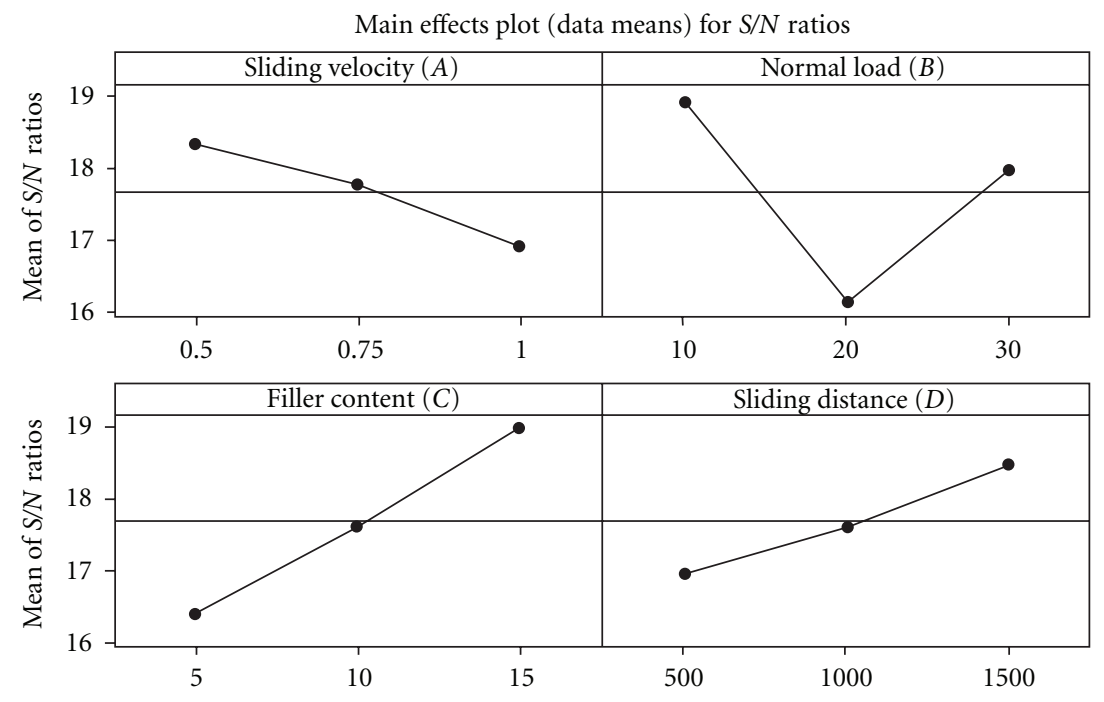

Signal-to-noise: smaller is better

(a)

Main effects plot (data means) for means
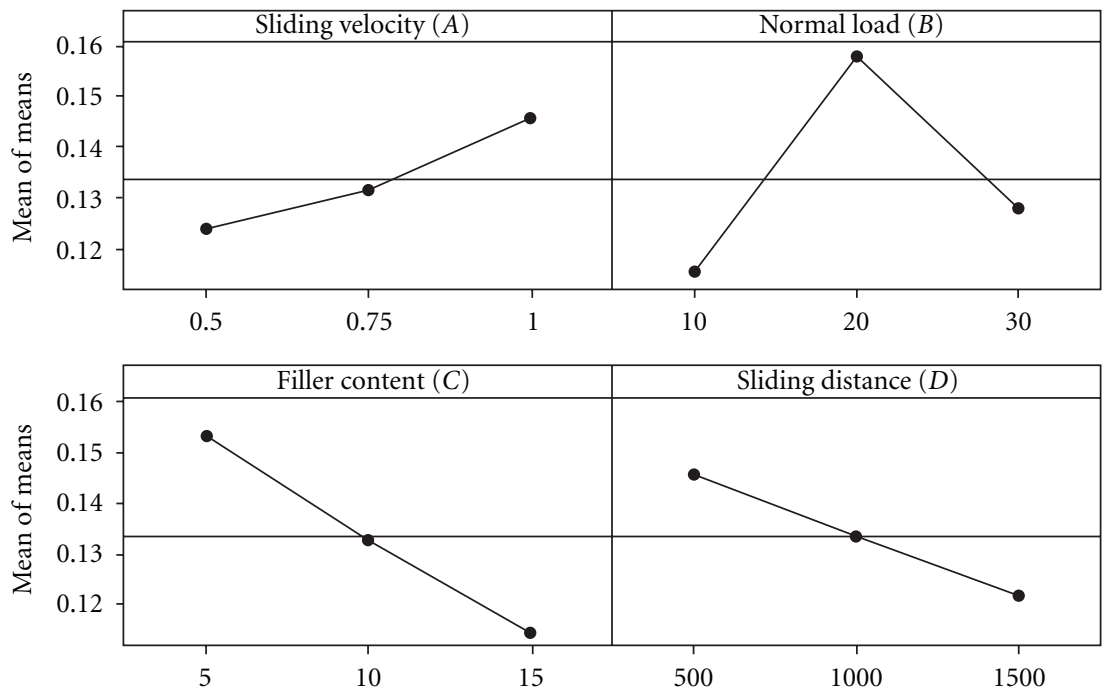

(b)

FIGURE 3: (a) Effect of control factors on wear rate ( $S / N$ ratio). (b) Effect of control factors on wear rate (mean).

obvious that change in the sliding conditions has a direct influence on the wear behavior of the composites. Increase in sliding velocity results in increased rubbing action at the composite and steel disc interface and consequently the wear rate increases. It is evident that wear rate has exhibited increasing and decreasing trend with the normal load. Increase in the normal load usually results in the thermal softening of the composite material and loosening of the matrix material which increases the wear rate. However, dislodging of the matrix material exposes the ceramic whiskers at the interface and these whiskers are able to take up the load applied there by reducing the wear rate at higher loads. This kind of variations in specific wear rate of polymer composites with the normal load is also reported by other researchers $[17,23]$. It is observed that increase in the level of both filler content and sliding distance causes wear rate to decrease with the effect of filler content dominating the effect of sliding distance on wear rate. Inclusion of the harder ceramic phase such as PTW results in lowering the wear rate of the composite. This is because the PTW being harder phase than the epoxy matrix improves the wear resistance property of the composite. It is understandable that increase in sliding distance (time of operation) causes the transfer film formation [28] on the wear disc and this contributes to reduce the wear rate under longer duration of sliding. In an effort to identify the role of ceramic particles in the wear behavior of polymer composites, Durand et al. [29] proposed several wear mechanisms such as surface cracking, particle detachment, thin and thick transfer layer at the interface, and so forth in case of polymer composites that provide 


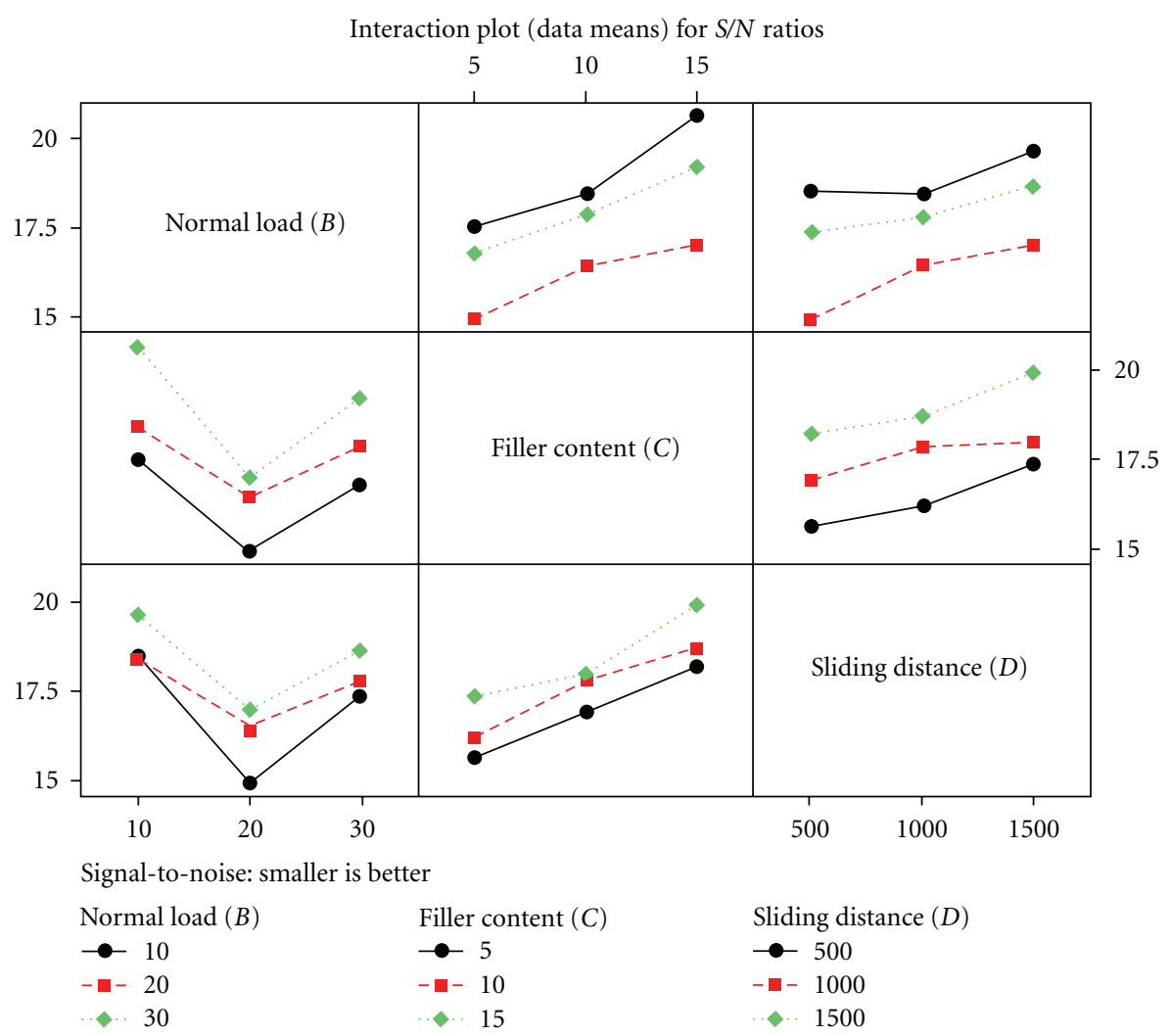

Figure 4: Interaction graph between $B, C$, and $D$ for wear rate.

the effective wear protection to the matrix material. Ray and Gnanamoorthy [30] explained that three mechanisms, namely: (i) matrix material loss; (ii) filler wear; and (iii) debonding at the interface are operative in filled polymer composites and dominance of one factor one over the other control the wear behavior of composites. In the present investigation, it was noticed that PTW particles, which are brittle in nature and also have sharp edges as obvious from SEM images, easily tear the matrix and progressively get aligned in the sliding direction. These particles by virtue of their shape, size, brittleness, and hardness modify the wear performance of the composites.

The $S / N$ ratio response is given in Table 4 , from which it can be concluded that among all the factors, normal load is the most significant factor followed by filler content, sliding distance, and sliding velocity. Analysis of the results leads to the conclusion that as far as minimization of wear rate is concerned, factors $A, B, C$, and $D$ have significant effect. Figure 4 illustrates the interaction effects of control parameters. It is well known that interactions do not occur when the lines on the interaction plots are parallel and strong interactions occur between parameters when the lines cross [31]. An examination of Figure 4 yields a small interaction between control parameters. In order to justify the insignificant factor and insignificant interaction a further statistical analysis (ANOVA) was carried out.

3.2. ANOVA and the Effects of Factors. ANOVA is a statistical design method used to break up the individual effects from
TABLE 4: Response table for signal to noise ratios.

\begin{tabular}{lcccc}
\hline Level & $A$ & $B$ & $C$ & $D$ \\
\hline 1 & 18.34 & 18.91 & 16.42 & 16.96 \\
2 & 17.77 & 16.15 & 17.61 & 17.61 \\
3 & 16.92 & 17.98 & 19.00 & 18.47 \\
Delta & 1.41 & 2.76 & 2.58 & 1.52 \\
Rank & 4 & 1 & 2 & 3 \\
\hline
\end{tabular}

all control factors. The percentage contribution of each control factor is employed to measure the corresponding effect on the quality characteristic. Table 5 shows the results of the ANOVA with the specific wear rate. This analysis was undertaken for a level of significance of $5 \%$ that is, for level of confidence $95 \%$. The 7 th column of Table 5 indicates the order of significance among factors and interactions. From Table 5, one can observe that the normal load $(P=0.000)$ has greater static influence of $38.67 \%$, filler content $(P=0.000)$ has an influence of $32.70 \%$, sliding distance $(P=0.002)$ has an influence of $11.34 \%$, and sliding velocity $(P=0.003)$ has an influence of $9.95 \%$ on specific wear rate. However, the interaction between normal load and filler content $(P=$ $0.200)$, normal load and sliding distance $(P=0.195)$, and lastly filler content and sliding distance $(P=0.432)$ show less significance of contribution on specific wear rate.

The present analysis indicates that dry sliding wear test parameters and their interactions have both statistical and physical significance (percentage contribution > error) in 
TABLE 5: ANOVA table for specific wear rate.

\begin{tabular}{|c|c|c|c|c|c|c|c|}
\hline Source & DOF & Seq SS & Adj SS & Adj MS & $F$ test & $P$ value & $P(\%)$ \\
\hline Sliding velocity $(A)$ & 2 & 9.1245 & 9.1245 & 4.5623 & 18.52 & 0.003 & 9.95 \\
\hline Normal load $(B)$ & 2 & 35.4780 & 35.4780 & 17.7390 & 71.99 & 0.000 & 38.67 \\
\hline Filler content $(C)$ & 2 & 30.0028 & 30.0028 & 15.0014 & 60.88 & 0.000 & 32.70 \\
\hline Sliding distance $(D)$ & 2 & 10.4056 & 10.4056 & 5.2028 & 21.11 & 0.002 & 11.34 \\
\hline$B \times C$ & 4 & 2.0655 & 2.0655 & 0.5164 & 2.10 & 0.200 & 2.25 \\
\hline$B \times D$ & 4 & 2.0972 & 2.0972 & 0.5243 & 2.13 & 0.195 & 2.29 \\
\hline$C \times D$ & 4 & 1.0942 & 1.0942 & 0.2736 & 1.11 & 0.432 & 1.19 \\
\hline Error & 6 & 1.4784 & 1.4784 & 0.2464 & & & 1.61 \\
\hline Total & 26 & 114.3166 & & & & & 100 \\
\hline
\end{tabular}

$\mathrm{S}=0.496392 \mathrm{R}-\mathrm{Sq}=98.39 \% \mathrm{R}-\mathrm{Sq}(\mathrm{adj})=93.02 \%$.

DOF: degrees of freedom; Seq SS: sequential sum of squares; Adj SS: adjusted sum of squares; Adj MS: adjusted mean squares; $P$ : percentage of contribution.

TABle 6: Confirmation test for specific wear rate.

\begin{tabular}{lcccc}
\hline & Initial process parameters & \multicolumn{2}{c}{ Optimal process parameters } & Improvement in the result \\
Level & $A_{1} B_{1} C_{2} D_{2}$ & Prediction & Experimental & $A_{1} B_{1} C_{3} D_{3}$ \\
& & $A_{1} B_{1} C_{3} D_{3}$ & 22.6135 & $3.74 \mathrm{~dB}$ \\
$S / N$ ratio $(\mathrm{dB})$ & 18.8755 & 22.3393 & 0.074015 & $34.97 \%$ \\
Specific wear rate $\left(\mathrm{mm}^{3} / \mathrm{N}-\mathrm{km}\right)$ & 0.113821 & 0.075656 & \\
\hline
\end{tabular}

the wear behavior of the Epoxy/PTW composites. However, interaction between filler content and sliding distance has statistical significance but do not have any physical significance [32-34], since error associated is more than percentage contribution of these interactions as evident from the ANOVA results.

3.3. Confirmation Experiment. The confirmation experiment is the final step in the design of experiment process. The purpose of the confirmation experiment is to validate the conclusions drawn during the analysis phase $[20,21]$. The estimated $S / N$ ratio for specific wear rate using the optimum level of parameters can be calculated with the help of the following predictive equation $[21,24,35]$ :

$$
\bar{\eta}_{\mathrm{opt}}=\bar{T}+\sum_{j=1}^{k}\left(\eta_{j}-\bar{T}\right) ; \quad j=1,2, \ldots, k,
$$

where $\bar{T}=$ overall experimental average of $S / N$ ratio. $\eta_{j}=$ mean of the $S / N$ ratio at the optimum parameter level. $k=$ number of main design parameters that significantly affect the wear rate of Epoxy/PTW composites. The predictive equation for the optimum wear parameters $A_{1}, B_{1}, C_{3}, D_{3}$ can be written as per

$$
\begin{aligned}
\bar{\eta}_{\mathrm{opt}}= & \bar{T}+\left(\overline{A_{1}}-\bar{T}\right)+\left(\overline{B_{1}}-\bar{T}\right)+\left(\overline{C_{3}}-\bar{T}\right)+\left(\overline{D_{3}}-\bar{T}\right) \\
& +\left[\left(\overline{B_{1}} \overline{C_{3}}-\bar{T}\right)-\left(\overline{B_{1}}-\bar{T}\right)-\left(\overline{C_{3}}-\bar{T}\right)\right] \\
& +\left[\left(\overline{B_{1}} \overline{D_{3}}-\bar{T}\right)-\left(\overline{B_{1}}-\bar{T}\right)-\left(\overline{D_{3}}-\bar{T}\right)\right] \\
& +\left[\left(\overline{C_{3}} \overline{D_{3}}-\bar{T}\right)-\left(\overline{C_{3}}-\bar{T}\right)-\left(\overline{D_{3}}-\bar{T}\right)\right]
\end{aligned}
$$

where $\overline{A_{1}}, \overline{B_{1}}, \overline{C_{3}}$, and $\overline{D_{3}}=$ mean response for factors and interactions at designated levels. By combining the similar terms, (4) reduces to

$$
\bar{\eta}_{\mathrm{opt}}=\overline{A_{1}}-\overline{B_{1}}-\overline{C_{3}}-\overline{D_{3}}+\overline{B_{1}} \overline{C_{3}}+\overline{B_{1}} \overline{D_{3}}+\overline{C_{3}} \overline{D_{3}} .
$$

The results of experimental confirmation using optimal wear parameters and comparison of the predicted wear rate with the actual wear rate using the optimal wear parameters are shown in Table 6. Good agreement seems to take place between the estimated and actual wear rate. The improvement in $S / N$ ratio from the starting level to optimum level is $3.74 \mathrm{~dB}$. The specific wear rate is reduced by $34.97 \%$. Therefore the wear performance is greatly improved by using Taguchi method.

\section{Conclusions}

Taguchi's robust design method can be used to analyze the dry sliding wear behavior of the polymer matrix composites as described in this paper. The following are general conclusions that can be drawn from the work.

(i) Design of experiment approach by Taguchi method enable us to analyze successfully the wear behavior of the composite with the sliding velocity, normal load, filler content, and sliding distance as test variables. From the $S / N$ ratio analysis, the optimal combination of wear parameters is obtained as $A_{1} B_{1} C_{3} D_{3}$ to minimize wear rate.

(ii) ANOVA results indicated that normal load is the factor which is having highest physical as well as statistical influence $(38.67 \%)$ on the wear of the composites followed by filler content $(32.70 \%)$, sliding distance (11.34\%), and sliding velocity (9.95\%). However, 
interactions of these factors have less significant effect on wear rate.

(iii) The confirmation tests indicated that it is possible to decrease wear rate significantly $(34.97 \%)$ by using the proposed statistical technique. The experimental results confirmed the validity of Taguchi method for enhancing the wear performance and optimizing the wear parameters under dry sliding conditions.

In future, this study can be extended to learn the wear behavior of similar multiphase polymer composites.

\section{Acknowledgments}

The authors extend thanks and appreciations to Director and Principal of St. Joseph Engineering College, Mangalore for their support and encouragement during research studies.

\section{References}

[1] S. T. Peters, Handbook of Composites, Chapman and Hall, London, UK, 2nd edition, 1998.

[2] C. A. Happer, Handbook of Plastics, Elastomers and Composites, McGraw -Hill, New York, NY, USA, 4th edition, 2004.

[3] J. V. Milewski and H. S. Katz, "Whiskers," in Handbook of Reinforcements for Plastics, pp. 205-229, Van Nostrand Reinhold, New York, NY, USA, 1978.

[4] X. Feng, X. Diao, Y. Shi, H. Wang, S. Sun, and X. Lu, "A study on the friction and wear behavior of polytetrafluoroethylene filled with potassium titanate whiskers," Wear, vol. 261, no. 1112, pp. 1208-1212, 2006.

[5] Y. Lin, C. Gao, and N. Li, "Influence of $\mathrm{CaCO}_{3}$ whisker content on mechanical and tribological properties of polyetheretherketone composites," Journal of Materials Science and Technology, vol. 22, no. 5, pp. 584-588, 2006.

[6] Y. Zhang, C. A. Pickles, and J. Cameron, "Production and mechanical properties of silicon carbide and alumina whiskerreinforced epoxy composites," Journal of Reinforced Plastics and Composites, vol. 11, no. 10, pp. 1176-1186, 1992.

[7] M. Avella, E. Martuscelli, M. Raimo, R. Partch, S. G. Gangolli, and B. Pascucci, "Polypropylene reinforced with silicon carbide whiskers," Journal of Materials Science, vol. 32, no. 9, pp. 2411-2416, 1997.

[8] S. Wang, S. Ge, and D. Zhang, "Comparison of tribological behavior of nylon composites filled with zinc oxide particles and whiskers," Wear, vol. 266, no. 1-2, pp. 248-254, 2009.

[9] B. Z. Jang, J. Y. Liau, L. R. Hwang, and W. K. Shih, "Structure-property relationships in thermoplastic particulate and ceramic whisker-modified epoxy resins," Journal of Reinforced Plastics and Composites, vol. 8, pp. 312-333, 1989.

[10] K. Suganuma, T. Fujita, K. Niihara, and N. Suzuki, "AA6061 composite reinforced with potassium titanate whisker," Journal of Materials Science Letters, vol. 8, no. 7, pp. 808-810, 1989.

[11] X. Feng, H. Wang, Y. Shi, D. Chen, and X. Lu, "The effects of the size and content of potassium titanate whiskers on the properties of PTW/PTFE composites," Materials Science and Engineering A, vol. 448, no. 1-2, pp. 253-258, 2007.

[12] L. F. Chen, Y. P. Hong, Y. Zhang, and J. L. Qiu, "Fabrication of polymer matrix composites reinforced with controllably oriented whiskers," Journal of Materials Science, vol. 35, no. 21, pp. 5309-5312, 2000.
[13] S. Chen, Q. Wang, T. Wang, and X. Pei, "Preparation, damping and thermal properties of potassium titanate whiskers filled castor oil-based polyurethane/epoxy interpenetrating polymer network composites," Materials and Design, vol. 32, no. 2, pp. 803-807, 2011.

[14] S. C. Tjong and Y. Z. Meng, "Performance of potassium titanate whisker reinforced polyamide-6 composites," Polymer, vol. 39, no. 22, pp. 5461-5466, 1998.

[15] Z. Zhu, L. Xu, and G. Chen, "Effect of different whiskers on the physical and tribological properties of non-metallic friction materials," Materials and Design, vol. 32, no. 1, pp. 54-61, 2011.

[16] M. Kumar, B. K. Satapathy, A. Patnaik, D. K. Kolluri, and B. S. Tomar, "Hybrid composite friction materials reinforced with combination of potassium titanate whiskers and aramid fibre: assessment of fade and recovery performance," Tribology International, vol. 44, no. 4, pp. 359-367, 2011.

[17] G. Y. Xie, G. X. Sui, and R. Yang, "The effect of applied load on tribological behaviors of potassium titanate whiskers reinforced PEEK composites under water lubricated condition," Tribology Letters, vol. 38, no. 1, pp. 87-96, 2010.

[18] G. S. Zhuang, G. X. Sui, H. Meng, Z. S. Sun, and R. Yang, "Mechanical properties of potassium titanate whiskers reinforced poly(ether ether ketone) composites using different compounding processes," Composites Science and Technology, vol. 67, no. 6, pp. 1172-1181, 2007.

[19] C. Douglas Montgomery, Design and Analysis of Experiments, John Wiley and Sons, New York, NY, USA, 5th edition, 2001.

[20] P. J. Ross, Taguchi Techniques for Quality Engineering, McGraw-Hill, New York, NY, USA, 2nd edition, 1996.

[21] R. K. Roy, A Primer on the Taguchi Method, Van Nostrand Reinhold, New York, NY, USA, 1990.

[22] M. H. Cho, S. Bahadur, and A. K. Pogosian, "Friction and wear studies using Taguchi method on polyphenylene sulfide filled with a complex mixture of $\mathrm{MoS}_{2}, \mathrm{Al}_{2} \mathrm{O}_{3}$, and other compounds," Wear, vol. 258, no. 11-12, pp. 1825-1835, 2005.

[23] Siddhartha, A. Patnaik, and A. D. Bhatt, "Mechanical and dry sliding wear characterization of epoxy- $\mathrm{TiO}_{2}$ particulate filled functionally graded composites materials using Taguchi design of experiment," Materials and Design, vol. 32, no. 2, pp. 615-627, 2011.

[24] A. Satapathy and A. Patnaik, "Analysis of dry sliding wear behavior of red mud filled polyester composites using the taguchi method," Journal of Reinforced Plastics and Composites, vol. 29, no. 19, pp. 2883-2897, 2010.

[25] Rashmi, N. M. Renukappa, B. Suresha, R. M. Devarajaiah, and K. N. Shivakumar, "Dry sliding wear behaviour of organomodified montmorillonite filled epoxy nanocomposites using Taguchi's techniques," Materials and Design, vol. 32, no. 8-9, pp. 4528-4536, 2011.

[26] American Society for Testing and Materials, "Standard test method for wear testing with a Pin-on-Disk apparatus," Tech. Rep. ASTM G99-05, American Society for Testing and Materials, 2010.

[27] Minitab User Manual, Making Data Analysis Easier, Minitab, Mishawaka, Ind, USA, 2001.

[28] S. Bahadur, "The development of transfer layers and their role in polymer tribology," Wear, vol. 245, no. 1-2, pp. 92-99, 2000.

[29] J. M. Durand, M. Vardavoulias, and M. Jeandin, "Role of reinforcing ceramic particles in the wear behaviour of polymerbased model composites," Wear, vol. 181-183, no. 2, pp. 833839, 1995.

[30] D. Ray and R. Gnanamoorthy, "Friction and wear behavior of vinylester resin matrix composites filled with fly ash particles," 
Journal of Reinforced Plastics and Composites, vol. 26, no. 1, pp. 5-13, 2007.

[31] P. Déprez, P. Hivart, J. F. Coutouly, and E. Debarre, "Friction and wear studies using taguchi method: application to the characterization of carbon-silicon carbide tribological couples of automotive water pump seals," Advances in Materials Science and Engineering, vol. 2009, Article ID 830476, 2009.

[32] S. Basavarajappa, G. Chandramohan, and J. Paulo Davim, "Application of Taguchi techniques to study dry sliding wear behaviour of metal matrix composites," Materials and Design, vol. 28, no. 4, pp. 1393-1398, 2007.

[33] P. Ravindran, K. Manisekar, P. Narayanasamy, N. Selvakumar, and R. Narayanasamy, "Application of factorial techniques to study the wear of $\mathrm{Al}$ hybrid composites with graphite addition," Materials and Design, vol. 39, pp. 42-54, 2012.

[34] S. R. Chauhan, A. Kumar, I. Singh, and P. Kumar, "Effect of fly ash content on friction and dry sliding wear behavior of glass fiber reinforced polymer composites-a Taguchi approach," Journal of Minerals \& Materials Characterization \& Engineering, vol. 9, no. 4, pp. 365-387, 2010.

[35] A. Patnaik, A. Satapathy, M. Dwivedy, and S. Biswas, "Wear behavior of plant fiber (pine-bark) and cement kiln dustreinforced polyester composites using Taguchi experimental model," Journal of Composite Materials, vol. 44, no. 5, pp. 559 $574,2010$. 

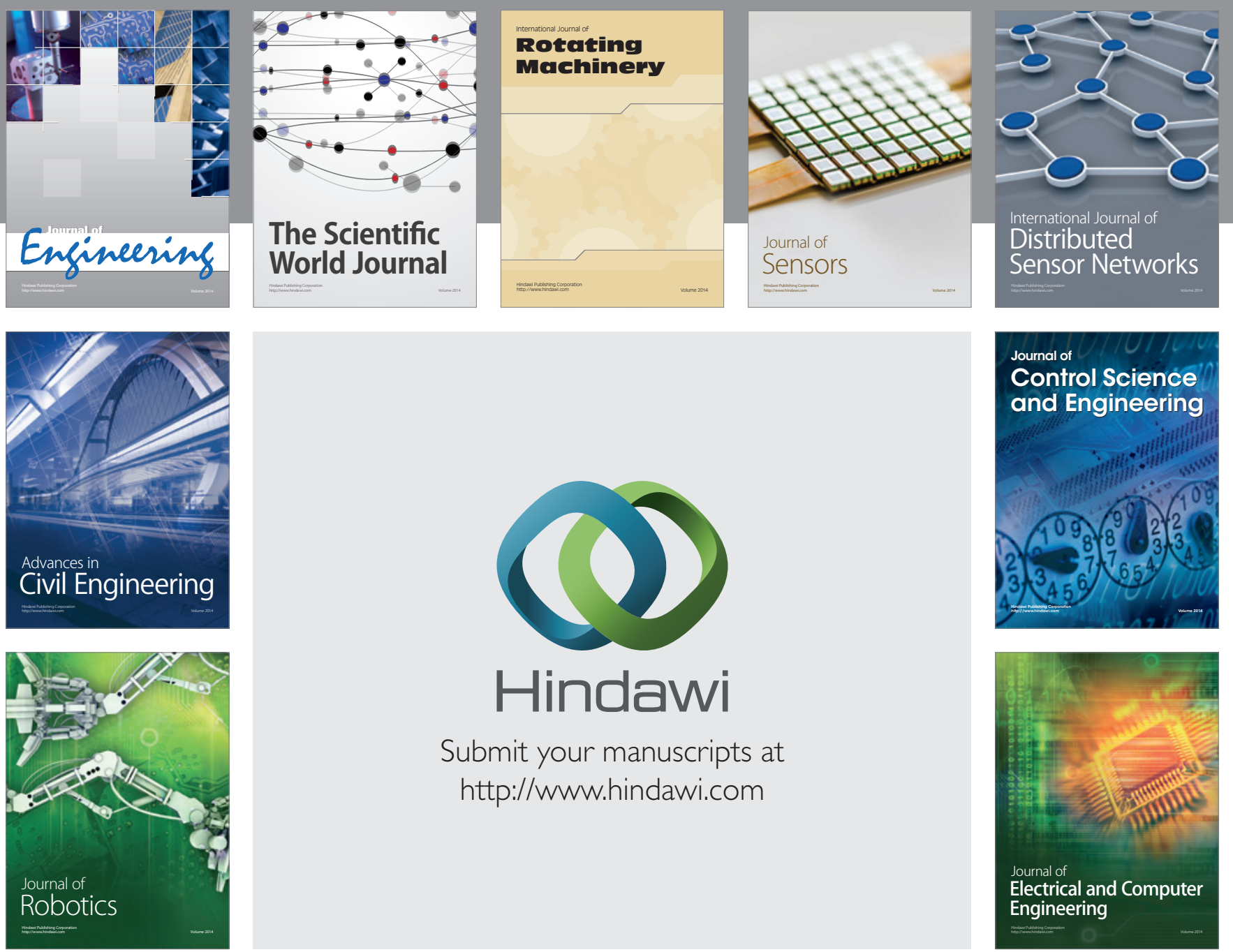

Submit your manuscripts at

http://www.hindawi.com
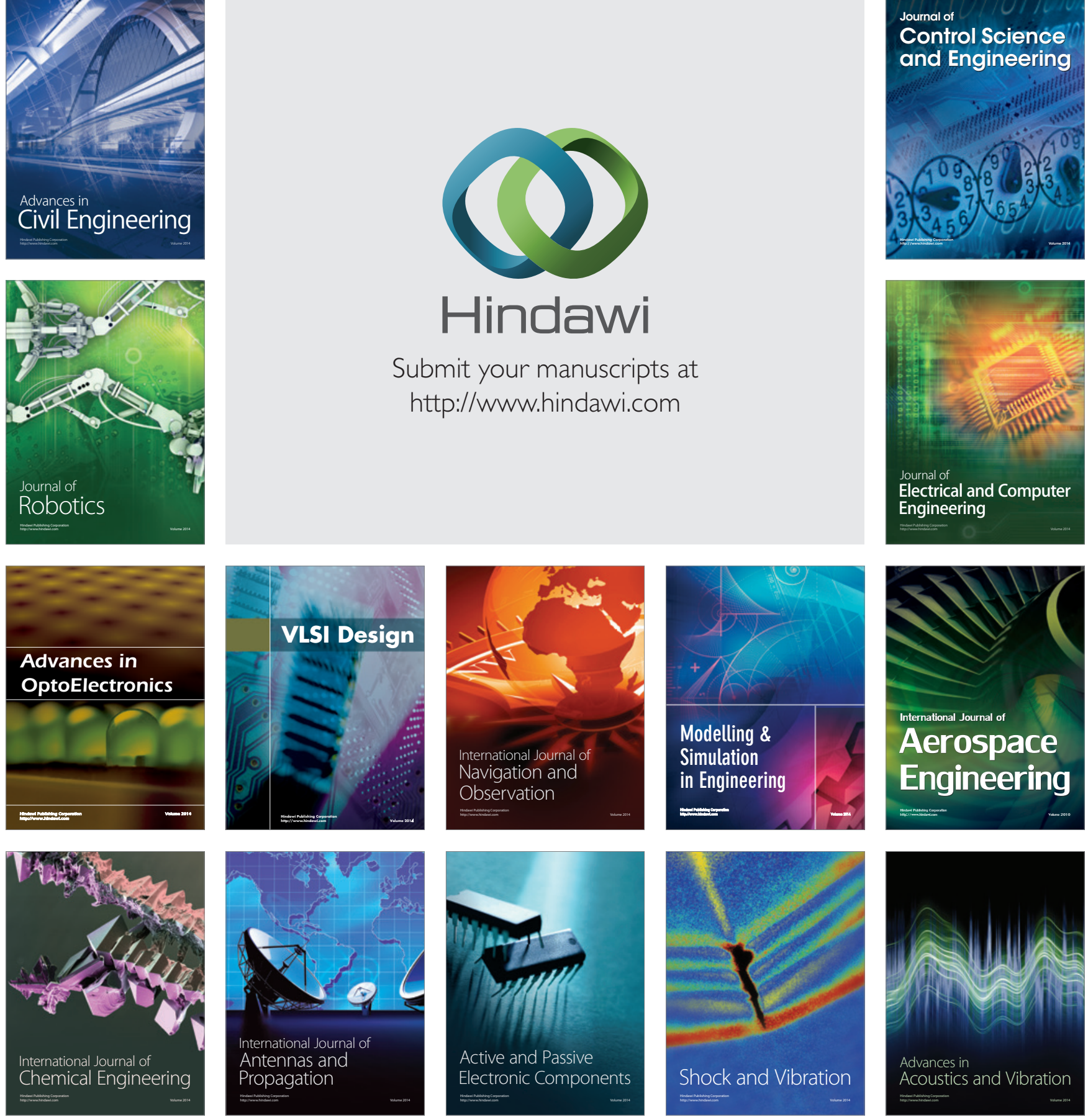